Results 551 responses were received. Participant mean age was $58.3 \pm 16.6$ years and age at diagnosis was $52.3 \pm 18.8$ years. $49 \%$ of patients had symptoms for $>6$ months before going to see a doctor and $22 \%$ were seen by 4 or more doctors before diagnosis. Time from first symptoms to diagnosis was $>1$ year in $49 \%$ with $31 \%$ of patients admitted as an emergency because of their symptoms. After diagnosis, $48 \%$ see a specialist at least every 6 months, $87 \%$ at least every 12 months. $62 \%$ think the support they receive is excellent and $26 \%$ good. $90 \%$ thought it was better to travel to a Specialist $\mathrm{PH}$ Centre rather than to be under the care of a non-PH specialist at a more local hospital.

Discussion This survey found that care of patients with $\mathrm{PH}$ is generally good or excellent and patients were keen to travel to Specialist PH Centres for their care. The early symptoms of pulmonary hypertension can be mild and are common to many diseases so it is often a lengthy process to arrive at the diagnosis. Compared with the previous survey the percentage of patients seeing $>4$ doctors before diagnosis was reduced (22\% vs $47 \%$ ) suggesting an increasing awareness of pulmonary hypertension amongst physicians. However, 49\% of patients had symptoms for $>6$ months before presenting, which has not improved since previous surveys. As earlier diagnosis of patients results in better long-term survival, further work should be undertaken to continue to raise awareness in the UK of pulmonary hypertension.

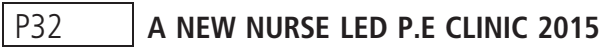

S Goodman. University Hospital Southampton, Southampton, UK

\subsection{6/thoraxjnl-2016-209333.175}

In 2015 Dr R Limbrey (Respiratory Physician) and Sr S.Goodman (CNS Pulmonary Vascular Service) set up a Nurse Led (new patient) Pulmonary Embolism (P.E) clinic to support increasing demand on the traditional model of consultant care.

We aim for a CNS review of all new patients with P.E at 3 weeks following diagnosis, and provide follow up for 2 years. Previously a CNS led follow up clinic was in place.

We aim to provide our patients with early high quality education and information to reduce anxiety, improve physical functioning and quality of life. We suggest that this will reduce perceived ongoing symptoms and lessen follow up requirement.

Referral is made electronically. The referral system has been developed as a learning opportunity to enable medical referrers to identify provoking factors and quantify risk associated with the event. The data obtained from referrals provides support for service provision.

In 2015, 260 patients were reviewed in the Nurse led clinic, 95 of these were new referrals.

Of the 95 new referrals to the service 54 (57\%) were provoked by an identifiable transient provoking factor. ESC (2014). Of these $42(78 \%)$ also had persistent risk factors by ESC

Unprovoked group:

The remaining 41 (43\%) had no identifiable transient provoking factor. Of these $32(78 \%)$ did have persistent risk factors as per ESC 2014.

We note that $44 \%$ of all identified PE patients in this cohort, provoked and unprovoked, had a BMI $\geq 30 \mathrm{~kg} / \mathrm{m}^{2}$

In the provoked group 16 new patients were reviewed and discharged after an average of 2.62 appointments per person with an additional telephone review planned at the 2 year point.
In the unprovoked group 12 patients have been discharged to date with an average of 3.3 appointments per person with an additional telephone review planned for the 2 year mark.

The remainder of these patients can reasonably be expected to be discharged from follow up with similar levels of review.

Feedback from our patients has been overwhelmingly positive, most commonly expressed as a significant reduction in anxiety and improvement in quality of life.

\begin{tabular}{llll} 
Abstract P32 Table 1 & & & \\
\hline $\begin{array}{l}\text { No of patients seen in Nurse led P.E } \\
\text { clinic } 2015 \text { by identified transient } \\
\text { provoking factors (new patients) }\end{array}$ & $\begin{array}{l}\text { No of } \\
\text { patients } 54\end{array}$ & $\begin{array}{l}\text { Persistent } \\
\text { in total }\end{array}$ & $\begin{array}{l}\text { No of } \\
\text { identified }\end{array}$ \\
\hline Post operative & $17 / 54$ & Obesity & $26 / 54$ \\
Travel & $11 / 54$ & Hypertension & $12 / 54$ \\
Immobility & $8 / 54$ & Previous VTE & $6 / 54$ \\
Pneumonia & $7 / 54$ & A.F & $2 / 54$ \\
Oral Contraceptive Pill & $4 / 54$ & Age $>80 y r s$ & $2 / 54$ \\
Pregnancy & $3 / 54$ & Known & $2 / 54$ \\
Cancer ( identified prior to diagnosis of & $1 /$ & Thrombophilia & \\
VTE) & & Tamoxifen & $0 / 54$ \\
Other & $3 / 54$ & Diabetes & $1 / 54$ \\
\hline
\end{tabular}

Unprovoked group:

\begin{tabular}{ll}
\hline $\begin{array}{ll}\text { Persistent risk factors identified in Nurse led P.E clinic 2015 in } \\
\text { Unprovoked group }\end{array}$ & $\begin{array}{l}\text { No of } \\
\text { patients }\end{array}$ \\
\hline Obesity & $16 / 41$ \\
Hypertension & $13 / 41$ \\
Previous VTE & $7 / 41$ \\
Age > 80 yrs at time of event & $8 / 41$ \\
Diabetes & $5 / 41$ \\
Known Thrombophilia & $2 / 41$ \\
Atrial Fibrillation & $1 / 41$ \\
Tamoxifen & $1 / 41$ \\
\hline
\end{tabular}

\section{P33 PATIENTS WITH PULMONARY ARTERIOVENOUS MALFORMATIONS AND HEREDITARY HAEMORRHAGIC TELANGIECTASIA REPORT FORCED EXPIRATORY MANOEUVRES DURING PULMONARY FUNCTION TESTS PROVOKE NOSEBLEEDS AND MIGRAINES}

${ }^{1} \mathrm{HC}$ Tighe, ${ }^{1} \mathrm{H}$ McKernan, ${ }^{1} \mathrm{JT}$ Springett, ${ }^{1} \mathrm{~L}$ Babawale, ${ }^{1} \mathrm{~J}$ Perks, ${ }^{2} \mathrm{~T}$ Patel, ${ }^{3} \mathrm{CL}$ Shovlin. ${ }^{1}$ Imperial College Healthcare NHS Trust, London, UK; ${ }^{2}$ St George's Hospital, London, UK; 3 Imperial College London, London, UK

\subsection{6/thoraxjnl-2016-209333.176}

Introduction and objectives Forced expiratory manoeuvres during lung function testing produce major pressure swings that are often overlooked by referring clinicians. Standard tests use a noseclip to prevent air leakage through the nose. Our goal was to examine how often the tests caused clinical sequelae such as nosebleeds in people with abnormal nasal and pulmonary vasculature due to hereditary haemorrhagic telangiectasia (HHT).

Methods With ethical approval, self-reported migraine features and exacerbations were examined in HHT subjects with and 